\title{
Prevalence of child injuries in Mbale region, Eastern Uganda
}

C.B.R. Ibingira1, J. Tumwiine'2, P. Nankabirwa'2, J. Nankunda².

1Principal Makerere college of health Sciences,

2Department of Paediatrics, School of Medicine,

Makerere University, College of health sciences, P.O Box 7072, Kampala Uganda

Correspondence to: Prof.Charles Ibingira BR, Email: cibingira@gmail.com

Background: The rate of unintentional child injuries in sub-Saharan Africa is at 53.1 per 100,000, The highest for low income regions, data on these injuries and associated factors among children in Uganda is very scanty. Most child injuries are related to the way of life in rural communities typically burns from charcoal stoves, candle light, hot fluids, chemicals, falls, and animal bites .

Methods: This was a cross sectional community survey among the Promise EBF participants in Mbale district of east Uganda.

Objective; to establish the prevalence, causes and associated factors of un-intentional child injuries in Mbale District.

Results: The commonest unintentional injuries were, falls, and burns $11 \%$ of the children. The main causes were hot water (43\%) and burning charcoal stoves/firewood. Predisposing factors to burns were residence in rural areas (OR 2.0; 95\% CI: 1.1, 3.5) and having three or more siblings (OR 1.6; 95\% CI: 0.9, 2.8) .. 40\% of the well off mothers and those with at least 8 years of education were more likely to report their child injuries. ((OR: 1.7; 95\% CI 1.0, 2.9) and (OR 1.5; 95\% CI 1.0, 2.2) respectively).

Conclusion: The prevalence of unintentional injuries among children of this cohort of mothers was high, caused by burns, falls, poisoning and animal bites.

\section{Introduction}

An injury is any physical damage that follows a sudden or brief subjection of the body to intolerable levels of energy, causing bodily lesions, This can follow an acute exposure to energy in amounts that exceed the threshold of physiological tolerance, or an impairment of function resulting from a lack of one or more vital elements such as water, oxygen, warmth, as in drowning, strangulation or freezing, or exposure to an uncontrolled physical release of energy like heat, electricity, gravity ${ }^{2}$. The term unintentional instead of accidental reflects a change in the understanding of injury.

Before 1940, most injuries were taken to result from carelessness, stupidity, or indifference ${ }^{3}$. Injury is among the leading causes of child death in developing countries. Injuries may be classified in a number of ways; according to whether or not they were deliberately inflicted and by what. For many purposes, including identifying intervention opportunities, this mode of classification has been found to be particularly useful ${ }^{4}$ and is used to classify injuries within the International Statistical Classification of Diseases and Related Health Problems ${ }^{10}$. According to the rules and conventions of ICD-10, injuries are included under external causes of mortality and morbidity. Within this broad grouping, injuries are subdivided into three main categories; Namely(14) Unintentional (i.e. Accidental).2) Intentional (i.e. Deliberate),interpersonal violence (e.g. Assault, homicide, intimate partner violence, sexual violence); self-directed violence or selfharm (e.g. Deliberate overdose of drugs and alcohol, self-mutilation, self-immolation, suicide);legal intervention like action by police or other law enforcement personnel; war, civil insurrection and disturbances during . Demonstrations and riots.3) Undetermined intention when it is difficult to judge whether an injury was inflicted intentionally or accidentally. 
Another frequently used method of classifying injuries is according to causal mechanism ,and these may include road traffic crashes, poisoning, falls, burns, drowning; fire arms, animal bites and domestic violence. The prevalence of child injuries in Uganda is not known or very scanty. There is a need for more reliable data on the nature and extent of injury to children in various geographical settings of Uganda. Also, Sound epidemiological data is essential not only for quantifying the magnitude of this public health problem, but for identifying risks, preventive measures and developing monitoring and prevention programmes. Injuries and violence are a significant and a growing cause of child death and disability, as well as having other health consequences including mental health, behavioral and reproductive health problems particularly in developing countries(29). Every year injuries and violence cause death of approximately 875000 children worldwide aged less than 18 years, and they continue to injure or disable tens of millions more(30). Injury-related causes account for 3 of the top 15 killers of children aged 0-4 years(12). The burden of child injury is most felt in low- and middleincome countries, of which Uganda is, where $95 \%$ of all child-injury deaths occur, and where recorded rates of child maltreatment are substantially more than four times higher than in high-income countries The rate of unintentional injuries for children in sub-Saharan Africa has reached 53.1 per 100,000, the highest for regions across all income levels ${ }^{5}$, in many parts of Africa where there has been escalation of fire arms and wars, child injuries worsened especially affecting the extremities and result into deaths and lifelong disabilities ${ }^{5,6}$.

The main objective of this study was to establish the prevalence, causes and associated factors of un-intentional injuries among the children of a cohort of mothers in the Promise EBF study in Mbale District of Uganda,

\section{Patients and Methods;}

This was a cross sectional community survey carried out among the Promise EBF participants in Mbale district located approximately $300 \mathrm{~km}$ North-East of Uganda. This area is mainly served by Mbale Hospital, that functioned both as the district and regional referral hospital. The population in this area consists largely of peasant farmers and a few urban dwellers. The study was conducted in the two counties, namely Bungokho County (rural) and Mbale Municipality (urban). Twenty four clusters were included in the study, 18 were rural and 6 were urban.. The participating mothers gave informed consent, and were taken through a questionnaire by the research assistant who filled in their responses. The corrected data was analyzed by starta using a logistic regression.

This study was carried out during the cluster-randomized PROMISE EBF intervention trial, where there was promotion of exclusive breastfeeding by individual peer counseling in the intervention areas (Clinical trials gov: NCT00397150) [17]. Data collection started in Uganda in 2006 and ended in January 2011. Children with confirmed injury whose mothers gave informed consent to participate in the study were involved. Consecutive children with a history of unintentional injuries were recruited into the study. Variables included demographic data from children and mothers, injuries sustained and etiological factors :

Data Analysis:

Stata version 9 (statacorp LP, TX, U.S.) was employed. The primary outcome was un-intentional injury, Exposure variables considered included mothers age, parity, mother's education, residence, household wealth index, number of children, gender of the children, . Crude odds ratios (OR) and 95\% confidence intervals were estimated for the exposure variables multivariable logistic regression was used to estimate the adjusted OR of the independent/exposure variables on the outcomes: unintentional injuries Initially, all these variables were included in the crude analyses. But, only variables that were associated with the outcomes yielding a P-value $<0.25$ or whose inclusion in the model resulted in a $10 \%$ difference 
in the beta estimates were retained in the final model. Frequencies and Odds ratios were calculated.

Approval was obtained from Faculty of medicine Research and ethics committee and informed consent was obtained from the parents and Legal guardians of the children. Confidentiality was strictly maintained.

\section{Results}

A total of 886 women were approached to participate in the study. Of these, 875 (98.8\%) accepted to participate in the study.

Table 1. Socio-demographic Characteristics and Predictors of Unintentional Injuries in a Cohort of 617 Children in Mbale, Eastern Ugandaa

\begin{tabular}{|c|c|c|c|c|}
\hline Characteristic & $\begin{array}{l}\text { Total } \\
\mathrm{N}=617 \\
\mathrm{n}(\%)\end{array}$ & $\begin{array}{l}\text { Unintentional } \\
\text { injuries } \\
\mathrm{N}=249 \\
\mathrm{n}(\%) \\
\text { (prevalence) }\end{array}$ & $\begin{array}{l}\text { Unadjusted } \quad \text { or }^{\mathrm{b}} \\
(95 \% \mathrm{CI})\end{array}$ & $\begin{array}{l}\text { Adjusted } \quad \text { orb }^{\mathrm{b}} \\
(95 \% \mathrm{CI})\end{array}$ \\
\hline \multicolumn{5}{|c|}{ Mother's Education } \\
\hline 0-7years & $435(71 \%)$ & $172(40 \%)$ & 1 & \\
\hline$\geq 8$ years & $182(29 \%)$ & $77(42 \%)$ & $1.1(0.8,1.6)$ & \\
\hline \multicolumn{5}{|l|}{ Residence } \\
\hline Rural & $481(78 \%)$ & $191(40 \%)$ & 1 & \\
\hline Urban & $136(22 \%)$ & $58(43 \%)$ & $1.1(0.8,1.7)$ & \\
\hline \multicolumn{5}{|c|}{ Household wealth index } \\
\hline Poorest 20\% & $125(20 \%)$ & $47(38 \%)$ & 1 & \\
\hline Middle $40 \%$ & $240(39 \%)$ & $100(42 \%)$ & $1.2(0.8,1.8)$ & \\
\hline Richest $40 \%$ & $252(41 \%)$ & $102(40 \%)$ & $1.1(0.7,1.8)$ & \\
\hline \multicolumn{5}{|c|}{ Children per mother } \\
\hline $0-2$ & 327 (53\%) & $125(38 \%)$ & 1 & 1 \\
\hline$\geq 3$ & $290(47 \%)$ & $124(43 \%)$ & $1.2(0.9,1.7)$ & $1.3(0.9,1.9)$ \\
\hline \multicolumn{5}{|c|}{ Mother's age in years } \\
\hline$\leq 19$ & $141(23 \%)$ & $57(40 \%)$ & 1 & \\
\hline $20-24$ & $191(31 \%)$ & $77(40 \%)$ & $1.0(0.6,1.6)$ & \\
\hline $25-29$ & 147 (24\%) & $60(41 \%)$ & $1.0(0.6,1.6)$ & \\
\hline$\geq 30$ & $148(22 \%)$ & $55(40 \%)$ & $1.0(0.6,1.6)$ & \\
\hline \multicolumn{5}{|c|}{ Marital Status of mothers } \\
\hline Married & $385(62 \%)$ & 147 (38\%) & 1 & \\
\hline Cohabiting & $179(29 \%)$ & $81(45 \%)$ & $1.4(0.9,1.9)$ & $1.5(1.0,2.3)$ \\
\hline Other & $53(9 \%)$ & $21(40 \%)$ & $1.1(0.6,1.9)$ & $1.3(0.7,2.6)$ \\
\hline \multicolumn{5}{|c|}{ Gender of infant } \\
\hline Girls & $304(50 \%)$ & $129(42 \%)$ & 1 & \\
\hline Boys & $308(50 \%)$ & $117(38 \%)$ & $0.8(0.6,1.1)$ & \\
\hline
\end{tabular}

A OR indicates odds ratio; $\mathrm{CI}$ indicates confidence interval

B Model adjusted for the cluster design of the study 
C includes single, widowed, divorced and separated

Table 2. Frequency of Unintentional Injuries Reported in a Cohort of 617 Children in Mbale, Eastern Uganda

\begin{tabular}{|l|c|c|}
\hline Injury & $\begin{array}{c}\text { Frequency of } \\
\text { injury } \mathrm{N}=617\end{array}$ & Prevalence (95\%CI) \\
\hline Falls & 173 & $28 \%(25 \%, 33 \%)$ \\
\hline Burns & 67 & $11 \%(9 \%, 14 \%)$ \\
\hline Poisoning & 3 & $0.5 \%(0 \%, 1 \%)$ \\
\hline Animal bites & 1 & $0 \%(0 \%, 0 \%)$ \\
\hline Cuts & 47 & $8 \%(6 \%, 10 \%)$ \\
\hline Fractures & 2 & $0 \%(0 \%, 1 \%)$ \\
\hline Skin tears & 38 & $6 \%(4 \%, 8 \%)$ \\
\hline Bruises & 140 & $23 \%(19 \%, 26 \%)$ \\
\hline
\end{tabular}

\section{Discussion}

Of the 886, 875 (98.8\%) accept. Seventy five participants were not eligible to participate in the Promise-EBF study after delivery for the following reasons: delivery of stillbirths (17), twin deliveries (17), maternal deaths (3), cleft, lip and cleft palate (1), infant deaths (28), and other reasons (13). One hundred and eighty three participants were lost to follow up, mostly because they relocated out of the study area. A total of 617 infants were interviewed about injuries and are included in this analysis.

On average, the mothers had 7 years of formal education (range 0 to 18 years). The median age of the children in this cohort was 19 months (ranging from 14 to 39) months, while the mean age of the mothers at the time of recruitment (during pregnancy) was 25years (ranging from 14 to 44 ) years. Mean and median parity was 3 and 2, respectively, ranging from 0 to 14 , with an inter-quartile range of 3 to 5.Table 1 summarizes other socio-demographic factors.

Nearly half of the infants in this cohort had at least one accidental injury in their past, though no death resulted, as compared to other studies in developing countries where accidental injuries are the commonest cause of death in children above one year (burns, poisoning, animal bites, fractures, cuts, skin tears and bruises) (Table 2)7.11. Children with three or more siblings were $30 \%$ more likely to have accidental injuries compared to those with two or fewer siblings (OR 1.3; 95\% CI: $0.9,1.9$ ). However in a study done in the US, the most prevalent injury was due to falls followed by scalds and poisoning the number of siblings was not associated to accident injury predictability 8.12 , falls accounted for $50 \%$ of all child injuries ${ }^{12}$.

There was no association between accidental injuries and maternal education (OR 1.1; 95\% CI: $0.8,1.6$ ) or residence (OR 1.1; $95 \%$ CI: 0.8, 1.7). The most commonly reported accidental/unintentional injuries were, falls, followed by burns (Table 2). Sixty seven (11\%) of the children had been burnt at least once. The most common causes of burns was hot water (43\%) and hot charcoal stoves/firewood (21\%). Other causes of burns included kerosene, candles, bushfires and hot drinks such as porridge. After adjusting for confounders, factors associated with burns were residence in rural areas (OR 2.0; 95\% CI: 1.1, 3.5) and having three or more siblings (OR 1.6; 95\% CI: 0.9, 2.8) (Table 3) and this agrees with other studies carried out for rural communities where Almost half of the world's population still relies on solid fuels wood, crop residues, animal dung and coal - for their everyday cooking and heating needs. A high proportion of these households burn the fuel in open fires, the most common device being 
a three stone fire place on the floor for cooking. There were 47 children that had ever been cut. The most common causes of cuts were razor blades $(55 \%)$ and knives $(28 \%)^{30}$. There was no association between cuts and maternal socio-demographic characteristics or the gender of the child as compared to one of the studies in Canada where a single marital status was a risk factor for boys ${ }^{7}$

Three children had been poisoned by drinking kerosene. All 3 were from rural areas. There were 13 birth injuries from 617 deliveries (2\%). Of these, 4 were scratch marks, 6 bruises, and 3 had weakness in the upper limbs, no birth related fractures were reported. It was not reported whether these were all hospital/health unit deliveries or not. Injuries resulting from road traffic accidents were not reported as most rural areas in eastern Uganda have few or no traffic.

In some developed countries, unintentional injuries account for $40 \%$ of all child hood deaths, though the prevalence in Uganda is not known , and in Japan, the causes are largely due to road traffic (motor vehicle crash),drowning ,poisoning and falls ${ }^{10,17,20}$, with more boys aged 1-4 years dying compared to girls, and for children less than one year the commonest cause of death is suffocation ${ }^{2}$ Wthe causes of injury in rural Uganda are ; burns, animal bites, falls and cuts.

In this cohort, 189 (31\%) of the children had received first aid at home for the injuries they suffered, however it was not indicated which anatomical areas were injured.16 (3\%) had received treatment at a health unit, one had been admitted at the district hospital and 3 had been treated by a traditional healer. There was no association between maternal sociodemographic characteristics (such as age, residence, education and socio-economic status) and health care seeking. Thirteen children (2\%) had not recovered from a previous injury. Unintentional injury is not caused by an accident but results from a complex interaction of predictable factors.. Knowledge of these factors that contribute to Pediatric Unintentional Injuries allows for the development of effective surgical nursing interventions and outcome evaluation. Injury outcomes can be avoided with strategies that minimize childhood risk factors, by maximizing injury modifying factors, and integrated perceived susceptibility.

\section{Conclusion}

Un intentional injuries are prevalent in Mbale rural communities of eastern Uganda, the types of unintentional injuries reported in this study, are very typical of rural settings that reflect the lively hood activities of families, as well as what constitutes the rural neighbor hood for childrenThe highest cause of unintentional injuries includes falls, and burns, followed by poisoning and bites, most burns were due to hot water, charcoal stoves and bush fires, and the more the siblings the more the likely hood of being injured. The anatomical sites commonly injured were not revealed. No deaths were reported . Maternal education, of more than 8years was associated to adequate reporting of all child injuries planned interventions should be aimed at reducing Burns and poisoning in rural areas

\section{Recommendations}

More studies, on unintentional child injuries , and the affected anatomical sites should be done to establish the prevalence in the country, especially aiming at collecting mortality and morbidity data to construct developmentally appropriate interventional strategies to guide pediatric anticipatory counseling on injury prevention topics appropriate and 
relevant to specific regions and child ages in Uganda as well as coming up with the appropriate legislation.

Acknowledgements;

The pep/promise project. for allowing us to use their cohort of mothers to collect data for this study.

\section{References}

1. (Polinder, Et al Prevalence and Prognostic Factors of Disability After Childhood Injury, Pediatrics Vol. 116 No. 6 December 1, 2005 pp. $e 8$-e 817

2. Hideaki Sekii,Tadahiro,Takako Shirawa Et al;Childhood Mortality Due to Unintentional Injuries in Japan, 2000-2009, nt J Environ Res Public Health. 2013 Feb; 10(2): 528-540. Published online 2013 Jan

3. Mónica Ruiz-Casares; Unintentional Childhood Injuries in Sub-Saharan Africa: An Overview of Risk and Protective Factors, Journal of Health Care for the Poor and Underserved, Volume 20, Number 4, November 2009 Supplement, pp. 51-67.

4. Campbell NM ${ }^{1}$, Colville JG, van der Heyde Y, Et al;;Firearm injuries to children in Cape Town, South Africa: impact of the 2004 Firearms Control Act. S Afr J Surg. 2013 Jul 31;51(3):92-6. doi: 10.7196/sajs.1220.

5. Wigton A. Firearm-related injuries and deaths among children and adolescents in Cape Town--1992-1996. S Afr Med J. 1999 Apr;89(4):407-10.

6. O'Shea JS;Childhood accident prevention strategies, Forensic Sci Int. 1986 FebMar;30(2-3):99111.

7. Kohen, D. E., Soubhi, H. \& Raina, P. 2000. Maternal reports of child injuries in Canada: trends and patterns by age and gender. Injury Prevention, 6, 223-228.

8. Agran $\mathrm{PF}^{1}$, Anderson C, Winn D, Et al;Rates of pediatric injuries by 3-month intervals for children 0 to 3 years of age. Pediatrics. 2003 Jun;111(6 Pt 1):e683-92.

9. Finkelhor , D. ( 1994), The international epidemiology of child sexual abuse . Child Abuse \& Neglect , 18, $409-417$.

10. Theurer WM1, Bhavsar AK.Am Fam Physician. Prevention of unintentional childhood injury.2013 Apr 1;87(7):502-9.

11. Charles Mock; Margie Peden; Adnan A Hyder;Et al, Child injuries and violence: the new challenge for child health; Bull World Health Organ vol.86 no.6 Geneva June 2008,

12. Adam R. Greenbauma, Jeremy Donneb, Diana Wilson b, et al, Intentional burn injury: an evidence-based, clinical and forensic review Burns 30 (2004) 628-642

13. Nagesh N. Julie Gilchrist, M. Dellinger, .et al Patterns of Unintentional Injuries among 0-19 Year Olds in the United States, 2000-2006

14. Ahmed A. Arif, M.D., Ph.D., Patti J. Patterson, M.D., M.P.H et al The Epidemiology of Unintentional Non-fatal Injuries Among Children in the South Plains/Panhandle Region of Texas. Texas Journal of Rural Health 2003; 21(2): 31-41

15. Miron D, Shinnawi F, Meenes R, Et al Childhood injuries in northern Israel prevalance and risk factors, Harefuah. 2003 Sep;142(8-9):579-82, 648.s

16. Unintentional Drowning: CDC Research \& Activities, Centre for disease control and prevention 2005-2009

17. Karestan C. Koenen , Andrea Roberts, Deborah StoneEt al;; The epidemiology of early childhood traum

18. Krug EG, Sharma GK, Lozano R: The global burden of injuries. American journal of public health 2000, 90(4):523-526. 
19. Cloitre , M. , Cohen, L. R. and Koenen, K. C. ( 2006). Treating the trauma of childhood abuse: Therapy for the interrupted life. New York: Guilford .

20. American Psychiatric Association . ( 2000 ). Diagnostic and statistical manual of mental disorders , 4th edition. Washington, DC : American Psychiatric Press .

21. Inter university Consortium for Political and Social Research . The National Co morbidity Study Replication. Public Use Data Set . http://www.icpsr.umich.edu/CPES/(accessed January 2010).

22. Kessler , R. C. , Berglund , P. , Chiu , W. T. et al. ( 2004 ).The US National Co morbidity Survey Replication(NCS-R): design and field procedures . International Journal of Methods in Psychiatric Research , 13, 69 -92.

23. Kessler , R. C. , Bergland , P. , Demier , O. et al. ( 1994 ).Lifetime prevalence and ageof-onset distributions of DSM-IV disorders in the National Co morbidity Survey Replication. Archives of General Psychiatry, 62 , 593 -602.

24. Kessler, R. C. and Ustun, T. B. ( 2004). The World Mental Health (WMH) Survey Initiative Version of the World Health Organization (WHO) Composite International Diagnostic Interview (CIDI) . International Journal of Methods in Psychiatric Research , 13, $93-121$.

25. Breslau, N. , Peterson, E. L., Poisson, L. M Et al ( 2004 ). Estimating post-traumatic stress disorder in the community: Lifetime perspective and the impact of typical traumatic events. Psychological Medicine, 34 , $889-898$.

26. Finkelhor , D. , Hotaling , G. Lewis , I. A. and Smith C. Et al. ( 1990 ). Sexual abuse in a national survey of adult men and women: Prevalence, characteristics, and risk factors . Child Abuse \& Neglect , 14, $19-28$.

27. Tjaden, P. and Thoennes, N. (2006). Extent, nature, and consequences of rape victimization: Findings from the national violence against women survey

28. joseph, k. e., adams, c. d., goldfarb, i. \& slater, h. 2002. parental correlates of unintentional burn injuries in infancy and early childhood. burns, 28, 455-463.

29. pearson, j., jeffrey, s. \& stone, d. 2009. varying gender pattern of childhood injury mortality over time in scotland. archives of disease in childhood, 94, 524-530.

30. Peden, m., mcgee, k. \& sharma. G. 2002. the injury chart book: a graphical overview of the global burden of injuries. geneva: world health organization, 5 . www.health.go.ug/docs/hssp_iii_2010.pdf

31.Bonnie R, Fulco C, Liverman C. Reducing the burden of injury: advancing prevention and treatment. get cited 1999, pg 319 